\title{
EVIDÊNCIA E INTERPRETAÇÃO EM PESQUISA: AS RELAÇÕES ENTRE QUALIDADES E QUANTIDADES ${ }^{1}$
}

\author{
Mariane Lima de Souza \\ William B. Gomes
}

\begin{abstract}
RESUMO. O estudo define e discute os conceitos de dado (data) e tomado (capta) em pesquisas cuja base empírica é constituída de quantidades (escalas, questionários, experimentos) e qualidades (descrições e entrevistas). Argumenta-se que dados são essencialmente diferentes de tomados e que a diferença encontra-se nas ligações lógicas entre evidência e interpretação. As ligações lógicas são definidas em termos de tropos de linguagem: similaridade (relações de causalidade), metáfora (relações de representação) metonímia (relações observáveis) e sinédoque (relações imagináveis). Tais ligações delimitam contextos nos quais quantidades e qualidades funcionam como partes móveis de um mesmo todo, sendo, portanto, instâncias reversíveis. Ressalte-se, contudo, que quantidades e qualidades apresentam especificidades lógicas de escolha e de julgamento que devem ser consideradas pelos pesquisadores. O exame das relações lógicas e comunicantes entre evidência e interpretação parece ser um recurso importante na sustentação de julgamentos em qualquer modalidade de pesquisa.
\end{abstract}

Palavras-chave: metodologia; epistemologia; fenomenologia-semiótica.

\section{EVIDENCE AND INTERPRETATION IN RESEARCH: RELATION BETWEEN QUALITIES AND QUANTITIES}

\begin{abstract}
This study defines and comments the concepts of given (data) and taken (capta) in empirical researches that are supported by quantities (scales, questionnaires and experiments) and qualities (descriptions and interviews). Our argument is that data are essentially different from capta and that the difference is placed in the logical relations between evidence and interpretation. Also, that logical relations are defined as language tropes: similarity (causality relations), metaphor (representation relations), metonymy (observable relations) and synecdoche (imaginative relations). The logical relations set a limit on contexts in which quantities and qualities work as moving parts from a whole, functioning as reversible instances. However, quantities and qualities preserve their logical specificity, which should be considered by the investigators. The exam of the communicational and logical relations between evidence and interpretation seems to be a useful resource to sustain the judgment decision in any kind of research study.
\end{abstract}

Key words: methodology; epistemology; semiotic phenomenology.

$\mathrm{O}$ uso de delineamentos combinados ou integrados de métodos quantitativos e qualitativos tem conquistado espaço considerável na pesquisa psicológica na última década. Pesquisadores de diversas áreas (Burman, 1997; Newman \& Benz, 1998; Niaz, 1997) têm concordado que é necessário um novo entendimento da relação entre métodos. Ao mesmo tempo, nota-se um esforço na clarificação de pressupostos epistemológicos de cada paradigma metodológico e no desenvolvimento de critérios independentes para julgar a legitimidade da pesquisa qualitativa.
O presente artigo examina modelos lógicos que servem de ligação entre evidência e interpretação em pesquisa. O contexto da discussão é a relação entre dados (data) e tomados (capta), cuja base empírica é constituída por quantidades e qualidades. O contexto de análise é a perspectiva da fenomenologia semiótica (Lanigan, 1988), uma expansão da fenomenologia existencial de MerleauPonty (1945/1999), recentemente denominada de comunicologia (Lanigan, 1992). Neste estudo, fenomenologia é definida como um método para trabalhar de modo sistemático com as próprias reflexões

\footnotetext{
1 Apoio: Capes/CNPq.
}

* Mestre em Psicologia pela UFRGS, doutoranda em Psicologia na mesma universidade. Pertence ao Núcleo de Estudos em Psicologia e Fenomenologia - UFRGS.

\# Doutor em Educação pela Southern Illinois University e professor de História da Psicologia e Métodos Qualitativos do Instituto de Psicologia da UFRGS. 
ou pensamentos. $\mathrm{O}$ ato de refletir apresenta-se em alguma forma de linguagem. Assim, justifica-se o interesse pela semiótica (Barthes, 1964/1971), enquanto estudo de sistemas de signos, tendo como base a relação destes signos entre si e com aqueles que os utilizam. A fenomenologia semiótica considera a relação entre teoria e metodologia, e entre evidência e interpretação, tanto do ponto de vista lógico, quanto do ponto de vista comunicativo. O problema lógico está no modo como o pesquisador considera qualquer associação entre, digamos, A e B e o seu respectivo contexto. Já o problema comunicativo aparece no modo como o pesquisador interpreta esta relação; por exemplo, o rigor de pertencimento contextual é preservado? Tais problemas ganharam certo destaque nas discussões sobre combinações de métodos quantitativos e qualitativos. Ademais, a abordagem fenomenológica semiótica enfatiza a importância da exigência ética em pesquisa, não somente no que se refere aos procedimentos legais, mas também a fazer justiça ao objeto em estudo. Por isso, ela não pode ser entendida simplesmente como uma abordagem concorrente com as demais, e sim como um recurso reflexivo e ético para lidar com a diferença e com a pluralidade.

O texto está organizado em quatro partes. Inicialmente revê propostas de delineamentos combinados ou integrados de métodos qualitativos e quantitativos, indicando propostas e práticas de articulação entre esses métodos. Em seguida examina as implicações epistemológicas no uso combinado dos métodos qualitativos e quantitativos, e também nas diferenças entre ciência natural e ciência humana. Os autores assumem que a diferença entre as referidas ciências não está no método, mas na articulação entre modos de evidência e modos de interpretação. A parte central do texto é dedicada à exposição de dois modelos lógicos que examinam a relação entre evidência e interpretação, ou entre observação (experiência) e sentido (compreensão), tendo como base de comparação a rigorosa definição de contexto. Por fim, introduz o conceito de reversibilidade para lidar com as relações simétricas, projetivas e transitivas entre evidência e interpretação, ilustrando a discussão com um exemplo de pesquisa empírica que se movimenta entre qualidades e quantidades.

\section{DELINEAMENTOS INTEGRADOS OU COMBINADOS DE MÉTODOS QUALITATIVOS E QUANTITATIVOS}

Uma síntese esclarecedora sobre diferentes visões de métodos qualitativos e das possíveis relações com métodos quantitativos foi apresentada por Guba e
Lincoln (1994). Os autores caracterizaram o uso de métodos qualitativos em três grandes grupos: construtivistas, sócio-históricos e pós-positivistas. Os construtivistas entendem que os dados de pesquisa são criados a partir da interação entre o investigador e o objeto de investigação, com o propósito de compreender consensos referentes a uma dada situação analisados através de recursos hermenêuticos e dialéticos. Os sócio-históricos, incluindo o materialismo dialético e as teorias feministas, usualmente subdivididos em pós-estruturalistas, pósmodernistas ou combinações entre ambos, concentram-se no estudo de transformações decorrentes da ignorância e da má compreensão de uma realidade que pode ser reapropriada através de revisões da história, com recursos dialógicos e dialéticos. Este grupo de pesquisadores assume a existência de uma identidade ideológica entre eles e os participantes da pesquisa. Por fim, os pós-positivistas defendem que a realidade deve ser exaustiva e criticamente examinada para que seja descrita e compreendida com justiça. Os achados, quando replicáveis, são provavelmente verdadeiros, mas sempre sujeitos a falsificação.

O método qualitativo, de acordo com Guba e Lincoln (1994), é básico para os construtivistas e sócio-históricos e atualmente é visto como uma complementação desejável para os pós-positivistas. O método quantitativo, por sua vez, é aceito pelos três grupos, por prover informações contextuais e comparativas indispensáveis.

Combinações de métodos qualitativos e quantitativos em pesquisa psicológica distinguem-se em duas vertentes. A primeira caracteriza-se pelo desenvolvimento de procedimentos combinatórios entre dois conjuntos de dados de natureza distinta, isto é, qualidades e quantidades (Dessen, 1994; Nelson, Wiltshire, Hall, Peirson \& Walsh-Bowers, 1995). A segunda concentra-se na superação de falsas associações combinatórias entre conjuntos de dados de natureza distintas, através de procedimentos integrativos entre qualidades e quantidades (Couto, 1999; Kuhn \& Lao, 1998; Newman \& Benz, 1999; Tolman \& Szalacha, 1999; Werle, 1989).

Nas proposições combinatórias a relação entre qualidade e quantidade é dicotômica e um conjunto de dados é usado como suporte para o outro. A comparação ocorre através da identificação de elementos quantitativos que possam contribuir para sustentar a generalização ou para corroborar predições apontadas em descritores qualitativos. Por exemplo, Dessen (1994) estudou interações e relações familiares, conjugando observação e entrevista. As análises qualitativas constituíram a primeira etapa da 
investigação, e foram seguidas de elaboração de sistemas de categorias. As categorias foram comparadas por critérios estatísticos. Do mesmo modo, Nelson, Wiltshire, Hall, Peirson e WalshBowers (1995) combinaram dados quantitativos e qualitativos para estudar a qualidade de vida de pessoas que estiveram hospitalizadas devido a problemas de saúde mental. Os dados quantitativos foram examinados através de estimadores estatísticos para fidedignidade e validade, enquanto os dados qualitativos foram examinados segundo sua confiabilidade (representação acurada, coerente ou replicável das visões dos participantes; coerente ou replicável e livre das pré-concepções do pesquisador). Finalmente, os achados qualitativos foram comparados aos achados quantitativos para examinar a convergência dos dois tipos de dados, e com achados de outros estudos.

Nas proposições integrativas a relação entre a abordagem qualitativa e a quantitativa é definida como seqüencial e inclusiva. Neste sentido, Tolman e Szalacha (1999) criticaram a pseudocombinação de métodos, ou seja, a condução de um estudo sob uma única rubrica, com o outro tipo de método servindo simplesmente como suporte ou ilustração. Em um estudo sobre a sexualidade adolescente feminina, as autoras discutiram a importância da adequação do método ao referencial teórico, reunindo as abordagens qualitativa e quantitativa em um procedimento denominado integração seqüencial. As autoras descrevem três análises distintas, mas sinergicamente relacionadas, de entrevistas com trinta estudantes norte-americanas, de 15 a 19 anos, divididas em dois grupos: escola pública de ensino médio do subúrbio e escola pública de ensino médio em uma área central da cidade. A primeira análise combinou dois métodos qualitativos: a análise narrativa (método interpretativo feminista) e a abordagem da teoria enraizada nos dados (grounded-theory). A segunda análise foi estatística e construiu uma matriz conceitualmente agrupada (análise de cluster) para identificar padrões intra e entre os grupos (adolescentes urbanas e suburbanas). A análise estatística sugeriu novas questões sobre o objeto investigado e levou a uma terceira análise: as pesquisadoras retornaram às transcrições originais das entrevistas e examinaram o texto completo de cada entrevista, expandindo a análise original interpretativa. Para finalizar, essas interpretações foram submetidas novamente a uma análise de cluster, que permitiu explorar e caracterizar as diferenças identificadas na análise estatística anterior entre as categorias identificadas. Esse último estudo ilustra uma posição alternativa, já refletindo em sua postura teórica uma crítica à pseudocombinação de métodos, ou seja, à condução de um estudo sob uma única rubrica, com o outro tipo de método servindo simplesmente como suporte ou ilustração.

Newman e Benz (1998) defenderam que interpretar a relação entre quantidades e qualidades como dicotômica é um equívoco. As autoras recapitularam que as pesquisas qualitativa e quantitativa procedem de diferentes raízes filosóficas, respectivamente, das teorias culturais e históricas e das positivistas. Como consequiência, o debate entre os pesquisadores gira em torno de suas diferenças quanto ao que é a realidade e quanto a ser ela mensurável ou não. Em última instância, esse debate leva a uma separação entre métodos objetivos e subjetivos como formas opostas de se compreender o que se conhece. Newman e Benz (1998) sustentaram que a conceituação dicotômica quantitativo-qualitativo não é consistente com uma coerente filosofia da ciência e que a noção de um continuum é o único construto que se ajusta ao que conhecemos de modo científico. Na perspectiva das autoras, o método científico contemporâneo deve ser indutivo e dedutivo, objetivo e subjetivo. As autoras partem do argumento de que os dois paradigmas coexistem no mundo da investigação e juntos formam um continuum interativo. Tal proposição implica uma definição de ciência que extrapola as definições tanto dos empiristas lógicos tradicionais quanto dos construtivistas. A pressuposição fundamental a essa proposta é que cada questão dita o método de pesquisa. A natureza da questão de pesquisa deve ditar o tipo de dado a ser coletado e o que fazer com os dados após a coleta. As autoras abordaram separadamente a pesquisa qualitativa e a pesquisa quantitativa, definindo-as em termos da diferença entre suas lógicas, respectivamente, indutiva e dedutiva.

Newman e Benz (1998) assumiram claramente uma posição epistemológica pós-positivista ao defenderem critérios diferenciados para a validação e legitimação de métodos qualitativos e quantitativos. Desta forma, as autoras diferem dos positivistas, que exigem os mesmos critérios de validação e legitimação para ambos os métodos, e dos pós-modernistas, para os quais nem toda pesquisa qualitativa conforma-se a critérios externos de validação e legitimação.

\section{IMPLICAÇÕES EPISTEMOLÓGICAS NO USO COMBINADO DOS MÉTODOS QUANTITATIVOS E QUALITATIVOS}

O uso de métodos quantitativos ficou associado, ao longo do tempo, a ciência natural ou positivista. Por sua vez, os métodos qualitativos apresentaram-se como alternativa metodológica para as ciências humanas. Pergunta-se, então: qual a relação entre estas 
duas ciências? Para Lanigan (1988), as ciências humanas são incorretamente tratadas como metodologicamente diferentes das ciências naturais, ao invés de essencialmente diferentes. A diferença no plano metodológico seria, basicamente, uma questão de método e lógica ou, em termos contemporâneos, práxis e teoria, ao passo que a diferença essencial seria uma questão que envolve a relação entre experiência (expressão) e consciência (percepção). Em outras palavras, trata-se da "diferenciação e integração de (1) ação retórica ou racional na sociedade e de (2) éticas ou normas de personalidade no mundo social" (p. 7). Enquanto a relação entre teoria e práxis caracteriza a diferença metodológica, a relação entre consciência e experiência na prática humana de pesquisa caracteriza a diferença essencial. Neste ponto é importante explicar as definições do autor para teoria e metodologia, bem como para os diversos conceitos derivados desses dois primeiros, a fim de esclarecer sua perspectiva final sobre a diferença entre ciências humanas e naturais.

Lanigan (1992) definiu teoria como um conjunto de afirmações que expressam os critérios normativos completos para a escolha de contextos de julgamento. Quando esses critérios são limitados (incompletos), eles constituem um modelo. Quando há somente um critério, ele define um construto, nesse caso, data (no latim, quod erat demonstrandum: aquilo que era para ser demonstrado) e capta (no latim, quod erat inveniendum: aquilo que era para ser descoberto). Data refere-se ao factual, o que é dado como evidência. Capta refere-se ao apreensível, o que é tomado como evidência. Como modelo, a teoria pode ser caracterizada pelo eidético (um processo ideacional ou conceitual - isto é, compreensão) ou pelo empírico (um processo de performance ou ações - isto é, realização). A construção de teoria eidética pode ser testada reflexivamente pela construção de teoria empírica e a construção de teoria empírica pode ser testada reflexivamente pela construção de teoria eidética (Lanigan, 1992). Metodologia, por outro lado, é um conjunto de ações que expressam o contexto normativo completo para fazer uma escolha (Lanigan, 1992), isto é, um sistema para a constituição ou produção de resultados. Quando o contexto é limitado (incompleto), constitui um procedimento (poiesis) ${ }^{2}$. Quando há somente um contexto conhecido, ele é um exemplar. O procedimento, qualitativo ou quantitativo, é definido pelo modelo teórico, respectivamente,

Segundo Lanigan (1992, p.212), o sinônimo moderno para poiesis é método, no mesmo sentido com que é empregado na expressão "método científico". eidético ou empírico. Fechando o ciclo, o exemplar protótipo ou paradigma - é definido pelo construto teórico, respectivamente, data ou capta. Metodologia e teoria estabelecem uma relação dialética através da qual a primeira recorre à segunda para construir um contexto particular, na forma de um sistema de procedimentos denominado método.

Desta forma, Lanigan (1992) definiu a metodologia quantitativa como a prática de um método de condição de verdade a fim de comparar e contrastar escolhas feitas em um contexto previamente determinado de dados (data - escolha de contexto restrita ou forçada) isto é: magnitude (Matemática), probabilidade (Estatística) ou possibilidade (Lógica). A metodologia qualitativa, por outro lado, caracterizase como a prática de um método de condição suficiente e/ou necessária a fim de comparar e contrastar escolhas feitas em um contexto tomado (capta - escolha de contexto aberta) que pode ser: formal ou fundamental (Fenomenologia), substancial (Semiologia), simbólico (Etnografia), ou artifactual (Historiografia).

$\mathrm{O}$ autor concluiu que a pesquisa qualitativa (humanística) é uma atividade simbólica na qual a "evidência" é mediada ao converter experiência (observação) em consciência (medida) (Lanigan, 1997, p.20). Tal evidência produzida é o capta, isto é, aquilo que é tomado como evidência, caracterizando a metodologia da descoberta. O benefício da pesquisa com a descoberta é o fato de que um julgamento qualitativo possibilita exatidão e abstração na descrição (representação). Em contraste, continua o autor, "no lado oposto da metodologia, a simbologia da prática de pesquisa pode ser 'evidência' que é mediada ao converter consciência ('medida') em experiência ('observação'), e chamando-a 'científica' ou 'realística"' (Lanigan, 1997, p.21, grifos do autor). Essa evidência produzida é designada como data, isto é, aquilo que é dado como evidência, caracterizando a metodologia da invenção. A vantagem da pesquisa com tal metodologia é o fato de que um julgamento quantitativo permite precisão e generalização (predição). Ainda segundo Lanigan (1997), a pesquisa naturalística, que tem no positivismo o seu fundamento epistemológico, requer uma teoria da informação onde o contexto de escolha é dado (data). Estabelecendo uma relação complementar, a pesquisa qualitativa (humanística), que tem na fenomenologia o seu fundamento epistemológico, requer uma teoria da comunicação onde se toma (capta) uma determinada escolha de contexto para se escolher o que faz sentido.

Em um estudo anterior, Lanigan (1988) definiu quatro etapas de investigação e suas diferenças para cada concepção de pesquisa. Assim, as ciências 
humanas, uma vez ocupadas com o capta, seguem um método de análise sistêmica que parte da hipótese (ou processo de descoberta) para a verificação (ou testagem de possibilidades), e chega à explicação (ou descrição dos resultados) e à proposição (ou compreensão). Já as ciências naturais, ocupadas com o data, seguem um método de análise sistemática, que parte da hipostatização (ou processo de invenção) para a verissimilitude (ou testagem de probabilidades), chega à explanação (ou predição de resultados) e, finalmente, obtém a afirmação (ou conhecimento).

O contraste entre descoberta - para a qual foi usado o termo hipótese - e invenção - para a qual foi usado o termo hipóstase - requer maiores esclarecimentos. O termo hipótese é de uso consensual tanto para formular perguntas para pesquisa quanto para formular possíveis explicações para os achados. O antigo termo hipóstase é mais raramente empregado e em geral usado para criticar determinadas práticas em ciência, como o descaso com a exigência ética, como mencionado por Bellino (1993/1997). No sentido usado acima o termo referese ao racionalismo instrumental, no qual o processo de invenção consiste em transformar, através de instrumentos, uma relação lógica numa substância, no sentido ontológico do termo (Lalande, 1996).

Todas essas distinções feitas pelo autor entre as duas abordagens (positivista e fenomenológica) de pesquisa (respectivamente, naturalística e humanística) tomam por base a diferença essencial, na mediação entre a consciência do pesquisador e seus dados, que perpassa metodologia e teoria. O pesquisador é posto em uma situação de intérprete de dados que foram de alguma forma observados ou constituídos por ele. A ordem com que o pesquisador faz a mediação entre consciência e experiência determina a diferença entre os dois paradigmas (Lanigan, 1997): "na prática de pesquisa, isso significa distinguir entre a ordem da experiência $(\mathrm{OE})$ e a ordem da análise $(\mathrm{OA})$, ou seja, o encontro com evidência (OE) do modo como aparece para a consciência versus o método (OA) de experienciar a evidência" (p.22).

$\mathrm{Na}$ abordagem fenomenológica, experiência é aquilo que é tomado em análise (capta). O pesquisador, voltado para a lógica inerente ao fenômeno, utiliza um método que inicia consigo (ordem da experiência) como um experienciador que experiencia o evento. Nessa ordem, a seqüência é experienciador/ experienciado/experienciado, e determina como a experiência veio à consciência. Para analisar o fenômeno (ordem da análise) o pesquisador deve inverter a sequiência anterior para: experienciado/ experienciando/experienciador, determinando como a experiência é tomada (capta) ou descrita. $\mathrm{Na}$ abordagem positivista, experiência é aquilo que é dado (data) anterior à análise. Assim, a ordem da experiência (OE) e a ordem de análise (OA) são ordens paralelas de julgamento. O pesquisador positivista dá (data) uma lógica ao fenômeno, com o objetivo de predizer se a atribuição permanecerá (hipóstase). A ordem de análise segue a mesma ordem da experiência: experienciador/experienciado/experienciado.

Segundo Lanigan (1988), a mediação entre consciência e experiência coloca em cena a dimensão comunicativa e ética da ciência, focalizando a relação entre teoria e práxis no pensamento e ação humanas. Tais relações fornecem o novo domínio de pesquisa voltado para o espaço de práxis comunicativa em que o sujeito está situado. Esse novo domínio de pesquisa encontra sua base fundamental na interface entre a fenomenologia e a semiótica. Enquanto a fenomenologia volta-se para a base empírica da experiência consciente e para a relação entre experiência (objeto) e consciência (sujeito), a semiótica especifica um modo de relação entre o percebido e o expresso, redefinindo a base real em um sistema de códigos (sinais e símbolos). A fenomenologia fornece o método para a compreensão de uma consciência que se mostra evidente através do gesto e da fala, por sua vez, objetos de estudo da semiótica. O foco de investigação, nesse caso, é o modo de praticar as possibilidades do argumento, isto é, a retórica ${ }^{3}$ do discurso.

\section{A LÓGICA DA RELAÇÃO ENTRE EVIDÊNCIA E INTERPRETAÇÃO.}

No contexto das ciências humanas, mais especificamente da fenomenologia semiótica, a lógica retórica da pós-modernidade substituiu a lógica gramatical da modernidade. Em outros termos, assumiu-se a distinção entre discurso e linguagem natural, nos termos da ciência humana francesa (Merleau-Ponty, 1945/1999), onde o discurso é definido como a linguagem natural assumida e transformada pelo sujeito falante. Essa distinção levou à dicotomia enunciação/enunciado, ou língua/fala, constituindo a práxis linguiística (Barthes, 1964/1971). $\mathrm{Na}$ fenomenologia, enunciação (modalidade expressiva de percepção) é intencionalidade (a consciência de), e enunciado é a condição resultante da enunciação (Lanigan, 1992). A comunicação tem, então, uma dimensão lingüística (retórica do discurso/fala) e uma dimensão atuante (retórica da

\footnotetext{
“Discurso como práxis” (Lanigan, 1992, p. 222).
} 
ação), ambas representadas, respectivamente, pelas quatro retóricas de Platão (maiêutica, retórica, sofística e dialética) e pelos tropos lógicos (metáfora, metonímia, sinédoque e ironia).

Essa relação entre experiência (observação) e consciência (compreensão) aparece com muita clareza em dois modelos de retórica que procuram dar conta da dimensão atuante da comunicação. São eles: a lógica dos tropos de linguagem, de Burke (1962), e a lógica pela qual os símbolos estão ligados, de Leach (1976/1978). Ambos os modelos especificam as mediações diretas e indiretas entre consciência e experiência, fornecendo critérios para distinguir as posições gerais sobre teoria de conhecimento.

\section{Lógica e tropos de linguagem}

Burke (1962) propõe que uma via de descoberta e descrição "da verdade" (grifo do autor), ou seja, de relação entre consciência e experiência, poderia ser empreendida através da utilização dos quatro principais tropos de linguagem: metáfora, metonímia, sinédoque e ironia. Os quatro tropos são definidos a seguir de acordo com Ferreira (1986):

Metáfora é o "tropo de linguagem que consiste na transferência de uma palavra para um âmbito semântico que não é o do objeto que ela designa, e que se fundamenta numa relação de semelhança subentendida entre o sentido próprio e o figurado" (p.1126). Por exemplo, chamar uma pessoa que tem uma bela voz de rouxinol.

Metonímia é o "tropo que consiste em designar um objeto por palavra designativa doutro objeto que tem com o primeiro uma relação de causa e efeito (trabalho, por obra), de continente e conteúdo (copo, por bebida), lugar e produto (porto, por vinho do Porto), matéria e objeto (bronze, por estatueta de bronze), abstrato e concreto (bandeira, por pátria), autor e obra (um Camões, por um livro de Camões), a parte pelo todo (asa, por avião), etc. (p.1128)".

Sinédoque é o "tropo que se funda na relação de compreensão e consiste no uso do todo pela parte, do plural pelo singular, do gênero pela espécie, etc., ou vice-versa (p.1590)". Por exemplo, empregar "os mortais" ao invés de "homens".

Ironia, por fim, é definida como "modo de exprimir-se que consiste em dizer o contrário daquilo que se está pensando ou sentindo (p.969)".

Os tropos aparecem na gramática como figuras de linguagem. No entanto, o empreendimento de Burke (1962) sugere a aplicação literal ou realística dos tropos de linguagem, em lugar de seu uso figurativo. O autor substitui, então, metáfora por perspectiva, metonímia por redução, sinédoque por representação e ironia por dialética.

A metáfora é considerada um artifício para ver alguma coisa em termos de outra coisa, e por isso funciona como perspectiva. Ela conta algo sobre um caractere como considerado do ponto de vista de um outro caractere. O termo caractere é definido por diversos conceitos: padrão, situação, estrutura, natureza, pessoa, objeto, ato, papel, processo, evento, e outros semelhantes. Desta forma, considerar A do ponto de vista de B é usar B como uma perspectiva para A. Usualmente, é pela aproximação por meio de uma variedade de perspectivas que se estabelece a realidade objetiva de um caractere. Entretanto, utilizar B como perspectiva para A envolve a transposição de um termo de um domínio para dentro do outro e estabelece um processo com variados graus de incongruência, uma vez que dois domínios nunca são idênticos.

Metonímia é considerada um artifício para exprimir algum estado incorpóreo ou intangível em termos do corpóreo ou tangível, sendo, portanto, uma redução. Um dos exemplos mais ilustrativos é o uso da palavra coração para falar de emoções. Todos os termos para estados espirituais foram metonímicos na origem. Enquanto a metonímia é um artifício do realismo poético, a redução é um artifício do realismo científico. O poeta sabe que as relações humanas requerem ações, que essas ações são dramatizações e que a essência do drama é a postura e a tonalização. Assim, a vergonha não é meramente um estado, mas também um movimento do olho ou uma cor de face. $\mathrm{O}$ poeta sabe, da mesma forma que um cientista do comportamento, que poderia reduzir o estado a estes equivalentes corporais correspondentes. Porém, ele não oferece sua metonímia como uma redução substancial. No realismo poético, os estados da mente, assim como os motivos de ação, não são redutíveis a termos materialistas. Entretanto, o poeta utiliza a metonímia como uma redução terminológica, enquanto o cientista oferece sua redução como a "verdadeira" redução. A redução é uma representação. Se um estado mental for considerado como a representação de certas condições materiais, pode-se dizer, revertendo o processo, que as condições materiais são representativas do estado mental. Se há correspondência entre o ato de percepção e a coisa percebida, cada um desses equivalentes pode ser tomado como representativo do outro. Desta forma, a redução (metonímia) sobrepõe-se à metáfora (perspectiva).

A sinédoque é considerada no mesmo sentido usual do dicionário: parte pelo todo, todo pela parte, 
continente por conteúdo, signo pelo significado, material pela coisa feita (o que a aproxima da metonímia), causa por efeito, efeito por causa, genes por espécies, espécies por genes, etc. Estas conversões implicam um relacionamento integral, de conversibilidade, entre os dois termos, por isso ela funciona como uma representação. $O$ conceito de sinédoque pode ser ampliado de forma a cobrir relações e seus reversos, como: antes por depois, implícito por explícito, seqüência temporal por seqüência lógica, título por narrativa, doença por cura, herói por vilão, ativo por passivo. Portanto, a metonímia pode ser tratada como um tipo especial de sinédoque. Por exemplo, após a analogia de uma correlação entre mente e corpo, ou consciência e matéria, seleciona-se qualidade e quantidade como um "par relacionado sinedoquicamente" (p. 509), pode-se então propor tratar como sinédoque a substituição de cada quantidade por qualidade ou qualidade por quantidade (desde que cada lado possa ser considerado como o signo, ou sintoma, do outro). A representação (sinédoque) reforça um relacionamento ou conexão entre dois lados de uma equação. Tal conexão pode ser compreendida como uma estrada que se estende em duas direções: de quantidade a qualidade ou de qualidade a quantidade. A redução, no entanto, segue somente em uma direção: de qualidade a quantidade. Burke (1962) afirma que é um erro tático postular o ideal quantitativo-matemático das ciências físicas como o ideal das ciências sociais. A ciência construída de acordo com esse modelo é restritiva, pois pretende explicar ordens mais altas por redução a ordens mais baixas, complexidades orgânicas por redução a simplismos atomísticos, substância por redução a movimento, ou qualidade por redução a número. Segundo ele, uma terminologia de análise conceitual deve ser construída em conformidade com um fato representativo considerando-se que fatos cientificamente selecionados para propósitos redutivos não são representativos. Notar que a redução da metonímia também se sobrepõe à representação da sinédoque.

$\mathrm{O}$ artifício da ironia trata do problema do fato representativo, e Burke (1962) o substitui por dialética. Para o autor, dialética e drama se equivalem. Um papel humano pode ser resumido em idéias que caracterizam a situação do agente: onde as idéias estão em ação, tem-se o drama; onde os agentes estão em ideação, tem-se a dialética. O relativismo é obtido pela fragmentação de cada drama ou dialética. Isolando-se um agente qualquer em um drama e vendo-se o todo em termos de sua posição sozinha, tem-se o puramente relativístico. Entretanto, relativismo não é ironia. A ironia surge quando alguém tenta, pela interação de termos, um sobre outro, produzir um desenvolvimento que utiliza todos os termos.

Para Burke (1962), o relativismo e a tendência da ironia em direção à simplificação de literalidade são tentações constantes da dialética ou do drama. A ironia tem um papel dual de adjetivo (incorpora uma das qualidades necessárias à definição total) e substantivo (incorpora as conclusões do desenvolvimento como um todo). O padrão básico da ironia - aquilo que vai adiante como A, retorna como não-A - coloca a essência do drama e da dialética na ironia do peripatético, isto é, o estratégico movimento do reverso. O movimento do reverso abre possibilidades profícuas para a reconsideração das relações entre qualidades e quantidades, como veremos no próximo item.

\section{Lógica e símbolo}

A mesma discussão apresentada por Burke aparece em Leach (1976/1978) em seu estudo sobre a lógica pela qual os símbolos estão ligados. O modelo de Leach é equivalente à proposta de Burke, mas com uma diferença: há uma inversão de ordem. Burke conclui sua exposição discutindo as relações de similitude (ironia), enquanto Leach inicia por essa discussão.

Para Leach (1976/1978), a comunicação humana é alcançada através de ações expressivas que operam relações definidas como sinais e índices. Sua exposição focaliza uma dada relação, que ele chama de "ocorrência da comunicação" entre duas entidades, por exemplo, entre A e B. O sinal é aquela relação na qual A causa $B$, onde a mensagem e a entidade que carrega a mensagem são dois aspectos da mesma coisa. Tem-se, então, a similitude de Leach e o par Símile/Ironia de Burke. O índice é aquela relação na qual $A$ indica $B$, correlacionando o presente (percepção) com uma ausência (imaginação). Nesta relação, não é possível distinguir o eidético do empírico.

$\mathrm{O}$ autor divide a classe dos índices em signum e índice natural. No signum, A está para B como resultado de uma escolha humana, isto é, a associação é uma convenção natural. A relação que se estabelece é de sinédoque: a contigüidade é imaginada, não existe um prévio relacionamento, pois o relacionamento é extrínseco - o signum é descontínuo e eidético. No índice natural, A está associado por natureza, mas selecionado como índice de $\mathrm{B}$ por escolha humana. A relação que se estabelece é de metonímia: o relacionamento é intrínseco, as relações são observáveis no mundo externo - o índice é 
contínuo e empírico, por exemplo, fumaça é um índice de fogo.

O signum comporta símbolos e signos. No símbolo, A representa B por uma relação arbitrária e as relações são observáveis no mundo interno (sinédoque). No signo, A representa B como parte de um todo, existindo uma relação intrínseca anterior, pois pertencem ao mesmo contexto cultural - os signos são sempre contíguos a outros signos que são membros do mesmo grupo (metonímia), por exemplo, coroa como símbolo de realeza.

A classe dos símbolos, por sua vez, divide-se em símbolo padronizado e símbolo particular, que, em oposição ao signo, estabelecem uma relação metafórica. No símbolo padronizado, a associação entre A e B é arbitrária, mas habitual, e as combinações dependem de transformações. Dentro dessa categoria encontram-se os ícones (onde a relação A/B é de semelhança planejada, por exemplo, modelos, mapas, retrato) e os símbolos convencionais (inteiramente arbitrários, por exemplo, serpente como símbolo do mal). No símbolo particular ou temporário, a associação entre A e B é completamente arbitrária, dependendo do emissor - a similaridade é atribuída.

\section{Em síntese}

A comparação entre ciências naturais e ciências humanas, explicada em termos de uma lógica dos tropos de linguagem ou da relação entre símbolos, fornece a base para um entendimento compreensivo da relação entre a quantidade - medida do instrumento, e a qualidade - medida do julgamento do pesquisador. Com efeito, trata-se da mesma relação que ocorre entre consciência e experiência, teoria e práxis, e linguagem e comunicação. Paralelamente, a breve referência ao contraste entre similitude factual e similitude imaginada da semiótica de Leach (1976/1978) configura uma importante diferença entre a lógica naturalista e a lógica humanística. Pode-se dizer que as lógicas das ciências naturais e das ciências humanas movimentam-se em sentido contrário (Gomes, 1993). A ciência natural parte de uma relação de similaridade (presentação) para uma relação metafórica (representação) e de uma relação metonímica (empírica) para sinedóquica (eidética). A produção do conhecimento centra-se no símile, uma vez que a investigação consiste na procura e estimação de semelhanças/diferenças. A discussão de resultados, entretanto, entra no pólo metafórico, uma vez que considera as semelhanças subentendidas. Nas ciências humanas a lógica será, então, o reverso. As ciências humanas partem de uma relação metafórica para uma relação de similaridade e/ou de uma relação de sinédoque (eidética) para uma relação de metonímia (empírica). A produção do conhecimento pode ter início no pólo da metonímia, no caso de inferência de associações por continuidade em que os dados (data) estão circunscritos a um mesmo contexto, ou, ainda, no pólo da sinédoque, no caso da inferência de associações possíveis em que os tomados (capta) ultrapassam os limites contextuais, constituindo-se em fatos da mente.

\section{A REVERSÃO ENTRE QUALIDADES E QUANTIDADES ENQUANTO MÉTODO DE PESQUISA}

$\mathrm{Na}$ perspectiva desse estudo, quantidades e qualidades são partes móveis de um mesmo todo. As partes podem assumir diferentes configurações e permitir diferentes visões, dependendo do ponto no qual esse determinado todo é percebido. Quantidades e qualidades compõem um campo figura-fundo, no qual o objetivo pode ser contexto para o subjetivo ou o subjetivo pode ser contexto para o objetivo, de acordo com o ponto de vista selecionado. Em outros termos, quantidades e qualidades estabelecem uma relação de sinédoque caracterizada pela reversibilidade.

Na Filosofia, o termo reversibilidade é definido como denominação de uma série ou processo que pode seguir a direção inversa, isto é, o predicado "é reversível" equivale ao predicado "não tem uma direção determinada" (Ferrater Mora, 1988). Na Psicologia, o conceito de reversibilidade surge ligado aos estudos desenvolvidos pela Gestalt sobre a relação entre forma e estrutura, especialmente sobre o problema figura e fundo. Köhler (1969/1978), seguindo observações feitas por um físico sobre a percepção visual de determinadas formas de figuras, direciona a atenção dos gestaltistas para o fenômeno das figuras reversíveis. As "figuras reversíveis" são figuras simples (como a clássica figura em forma de cruz dentro de um círculo) que, quando fixadas no centro pelo olhar durante algum tempo, apresentam uma reversão: a parte da estrutura que é percebida como a figura desaparece de repente, e a outra parte se transforma em figura. $\mathrm{O}$ processo se repete continuamente, pois, passado mais algum tempo, a primeira figura substitui a outra, e assim por diante (Köhler, 1969/1978).

Nesta análise, o termo reversibilidade pode ser ilustrado pela metáfora das figuras reversíveis fornecida pela Gestalt e é utilizado no mesmo sentido literal dado por Lazarte (2000): forma de superação da fragmentação dualista, não pela eliminação dos opostos numa visão indiferenciada, ou pela superação da síntese dialética, mas pelo trânsito dinâmico entre os aparentes extremos de uma mesma dimensão. Segundo este último autor, a 
perspectiva oferecida pela reversibilidade não se restringe à análise de pontos positivos e negativos de uma alternativa, mas abrange uma visão dos pólos como parte integral da dimensão analisada. A reversibilidade, como o trânsito entre polaridades, se apresenta como alternativa metodológica à questão de como manter a não-divisão da interpretação da realidade em fragmentos cognitivos, sem deixar de observar, conhecer, reconhecer e distinguir todas atividades que implicam divisão (Lazarte, 2000).

O sentido que emerge da relação entre experiência e consciência é constituído através de reversões apontadas pela lingüística (Lanigan, 1979), como as que ocorrem entre sintagma e paradigma (sintaxe), metonímia e metáfora (semântica), e diacronia e sincronia (pragmática). Sintagma, metonímia e diacronia são funções empíricas que operam em uma lógica binária (excludente: ou...ou). Em contraste, paradigma, metáfora e sincronia são funções eidéticas, que operam através de uma lógica analógica (inclusiva: e...e). As mesmas relações aplicam-se a quantidades e qualidades. Desta forma, quantidades e qualidades têm o status de identidade de classe, isto é, elas são reflexivas (uma requer a outra), simétricas (uma é diferente da outra), e transitivas (o conteúdo de uma classe reverte para outra sem perder a diferença de classe).

A idéia da reversibilidade como modelo para a pesquisa psicológica articula qualidades e quantidades, respeitando a diferença lógica entre uma e outra abordagem. As lógicas dedutiva e indutiva não são tomadas como critério de diferenciação e de especificação entre os métodos. A conjunção lógica se amplia, incluindo, além da indução e da dedução, a abdução e adução. Desta forma, o modelo da reversibilidade pressupõe que a pesquisa inicia-se de um movimento intuitivo (lógica abdutiva), que é transformado em um aparato de verificação através de experimento, questionário, protocolo de observação, protocolo de entrevista, etc., para constituir um corpus empírico (lógica indutiva). O material coletado é então analisado seja por quantificação seja por qualificação (lógica dedutiva), obtendo-se os resultados que sustentarão a discussão e conclusão dos achados. A grande maioria das pesquisas encerra-se neste ponto, quando muito apontando para a possibilidade de outros estudos. $\mathrm{O}$ modelo que está sendo apresentado vai além, ao exigir que os achados obtidos em um determinado contexto e epistemologia sejam questionados em outro contexto e epistemologia. Como exemplos de pesquisas que incorporam alguns destes passos lógicos podem ser citados Gomes, Reck, Bianchi e Ganzo, (1993). Hill, Gauer e Gomes (1998), Magalhães, Straliotto, Keller e Gomes (2001).

\section{CONSIDERAÇÕES FINAIS}

Atualmente, conforme indicado em nossa breve revisão, o uso de um delineamento misto de pesquisa, que consiste, basicamente, em uma comparação entre dados qualitativos e quantitativos, é a forma de integração metodológica mais freqüentemente encontrada nas pesquisas psicológicas. Entretanto, a relação entre a abordagem qualitativa e a quantitativa ainda é dicotômica, uma vez que o objetivo final é generalizar ou atribuir valor de predição aos achados qualitativos através dos resultados quantitativos. O delineamento misto, nesses casos, parece resultar em prejuízo para uma das abordagens, pois um método é utilizado apenas como um acessório ou suporte secundário para o outro. No caso da abordagem quantitativa, ela termina perdendo seu valor de predição e, conseqüentemente, a principal contribuição do método quantitativo à pesquisa. $\mathrm{O}$ prejuízo para a abordagem qualitativa, se utilizada somente como procedimento piloto no desenvolvimento de uma pesquisa cujo escopo é a quantificação, é dissociá-la de seu papel de descrição e compreensão do objeto de estudo.

O modelo da reversibilidade parte do pressuposto de que existe uma possibilidade de unir as duas abordagens de pesquisa em um mesmo plano de investigação, sem prejuízo para nenhuma delas. Para tanto, foi necessário identificar as diferentes premissas epistemológicas que embasam as duas abordagens de pesquisa e reconhecer a diferença não como um ponto de oposição instransponível, mas como uma possibilidade de complementação disponível. Por um lado, tem-se uma teoria da informação determinando uma metodologia de pesquisa que oferece ao sujeito um contexto pronto, no qual ele fará suas escolhas e que requer a quantificação (caracteriza a ciência natural). De outro lado, tem-se uma teoria da comunicação determinando uma metodologia de pesquisa que oferece ao sujeito a possibilidade de escolher o contexto a partir do qual pretende se situar e que requer qualificação (caracteriza a ciência humana).

$\mathrm{O}$ pesquisador em psicologia pode fazer escolhas teóricas que o direcionem apenas para um dos lados. São essas escolhas que determinarão o procedimento metodológico a ser seguido. A exigência é que a escolha teórica deve estar em consonância com o problema de pesquisa.

Caso o pesquisador opte pelo modelo da reversibilidade, então a escolha teórica é uma questão de postura ética do pesquisador: ele se move segundo uma retórica ética, isto é, tem sensibilidade para a ambigüidade e gosto pela evidência (Lanigan, 1988). A ambigüidade é uma escolha feita no discurso e pode ser boa ou má. A retórica ética constitui uma condição de boa 
ambigüidade, ou seja, é a experiência consciente da pessoa que constrói a situação de comunicação. A má ambigüidade é uma condição da ética retórica, ou seja, é a regulação da experiência consciente per se, de forma arbitrária. A dimensão comunicativa apresenta-se como a mediadora entre evidência e interpretação para definir as relações entre qualidades e quantidades.

\section{REFERÊNCIAS}

Barthes, R. (1971). Elementos de semiologia. (I. Blikstein, Trad.) São Paulo: Cultrix. (Trabalho original publicado em 1964).

Bellino, F. (1997). Fundamentos da bioética (N. S. Canabarro, Trad.). Bauru: Edusc. (Trabalho original publicado em 1993)

Burke, K. (1962). A grammar of motives and a rethorical of motives. Cleveland: The World Publishing Co.

Burman, E. (1997). Minding the gap: Positivism, psychology, and the politics of qualitative methods. Journal of Social Issues, 53, 785-801.

Couto, L. F. (1999). Feyerabend e a máxima do "tudo vale": a necessidade de se adotar múltiplas possibilidades de metodologia na construção de teorias científicas. Psicologia: Reflexão e Crítica, 12, 585-603.

Dessen, M. A. (1994). Interações e relações no contexto familiar: questões teóricas e metodológicas. Psicologia: Teoria e Pesquisa, 10, 213-220.

Ferrater Mora, J. (1988). Dicionário de Filosofia ( 4 Vols.) Madrid: Alianza Editorial.

Ferreira, A. B. de H. (1986). Novo Dicionário Aurélio da Lingua Portuguesa. Rio de Janeiro: Editora Nova Fronteira.

Gomes, W. B. (1993). As questões epistemológicas e a formação do pesquisador na pós-graduação brasileira. Em Pauta, 7, 3-25.

Gomes, W. B., Reck, A. C., Bianchi, A. S., \& Ganzo, C. C. (1993). O uso de indicadores quantitativos e descritores qualitativos na pesquisa em psicologia. Psicologia: Teoria e Pesquisa, 9, 415-433.

Guba, E. G. \& Lincoln, Y. S. (1994). Competing paradigms in qualitative research. In N. K. Denzin \& Y. S. Lincoln (Orgs.), Handbook of qualitative research (pp. 105-117). Califórnia: Sage.

Hill, E., Gauer, G., \& Gomes, W. (1998). Uma análise semiótico-fenomenológica das mensagens auto-reflexivas de filhos adultos de alcoolistas. Psicologia: Reflexão e Crítica, 11, 93-116.

Köhler, W. (1978). Desenvolvimentos recentes na psicologia da Gestalt (J. S. De Camargo Pereira, Trad.). In A. Engelmann (Org.) \& F. Fernandes (Coord.), Wolfgang Köhler (p. 164-
207). São Paulo: Editora Ática. (Trabalho original publicado em 1969)

Kuhn, D. \& Lao, J. (1998). Contemplation and conceptual change: integrating perspectives from social and cognitive psychology. Developmental Review, 18, 125-154.

Lalande, A. (1996). Vocabulário técnico e crítico da filosofia (F. S. Correia, M. E. V. Aguiar, J. E. Torres \& M. G. Souza). São Paulo: Martins Fontes.

Lanigan, R. L. (1979). A semiotic metatheory of human communication. Semiotica, 27, 293-305.

Lanigan, R. (1988). Phenomenology of communication: Merleau-Ponty's thematics in communicology and semiology. Pittsburgh: Duquesne University Press.

Lanigan, R. (1992). The human science of communicology. Pittsburgh: Duquesne University Press.

Lanigan, R. (1997). Capta versus data: método e evidência em comunicologia. Psicologia, Reflexão e Crítica, 10, 17-45.

Lazarte, L. (2000). Ecologia cognitiva na sociedade de informação. Ciência da Informação, 29. Disponível em: http://www.scielo.br .(Acessado em 07/11/2001)

Leach, E. (1978). Cultura e comunicação (C. R. Oliveira, Trad.). Rio de Janeiro: Zahar Editores. (Trabalho original publicado em 1976).

Magalhães, M., Straliotto, M., Keller, M., \& Gomes, W. (2001). Eu quero ajudar as pessoas: a escolha vocacional em psicologia. Psicologia, Ciência e Profissão, 21(2), 10-27.

Merleau-Ponty, M. (1999). Fenomenologia da percepção. (C. A. Ribeiro de Moura, Trad.) São Paulo: Freitas Bastos. ( Trabalho original publicado em 1945)

Nelson, G., Wiltshire, C., Hall, G. B., Peirson, L. \& WalshBowers, R. (1995). Psychiatric consumer/survivors' quality of life: quantitative and qualitative perspectives. Journal of Community Psychology, 23, 216-233.

Newman, I. \& Benz, C. R. (1998). Qualitative-quantitative research methodology: exploring the interactive continuum. Carbondale: Southern Illinois University Press.

Niaz, M. (1997). Can we integrate qualitative and quantitative research in science education? Science and Education, 6, 291-300.

Tolman, D. L. \& Szalacha, L. A. (1999). Dimensions of desire: bridging qualitative and quantitative methods in a study of female adolescent sexuality. Psychology of Women Quarterly, 23, 7-39.

Werle, F. O. C. (1989). Metodologias qualitativas e quantitativas: opção ou oposição. Estudos Leopoldenses, 25, 113-114.

Recebido em 27/03/2003

Aceito em 18/11/2003

Endereço para correspondência: William B. Gomes, Programa de Pós-Graduação em Psicologia do Desenvolvimento - UFRGS, Rua Ramiro Barcelos, 2600/113, 90035-003, Porto Alegre-RS. E-mail: gomesw@ufrgs.br 